\title{
LA PRENSA CATÓlica CATALANA DE 1868 A 1900 (I)
}

\author{
Solange HIBBS-LISSORGUES \\ Universidad de Toulouse-Le Mirail
}

\section{I.- Militancia de la prensa católica catalana durante el sexenio.}

El entorno socio-cultural de la segunda mitad del Siglo XIX impulsó a la Iglesia Española a cuestionar la validez de sus medios tradicionales de control sobre las mentalidades. Siempre desde una postura defensiva y de añoranza de épocas pasadas en las que su control era omnipresente en la sociedad, la Iglesia afirma la necesidad de acudir a nuevos instrumentos que pudiesen contrarrestar la progresiva descritianización. Sin abandonar la oración y la predicación, la Iglesia propone nuevas estrategias para la defensa de la "verdad" frente al "error" y afirma que los católicos deben echar mano de las mismas armas que utiliza el enemigo: la prensa. Aunque considera que la prensa es la mayor plaga de la época, la Iglesia no deja de recalcar la apremiante necesidad de adaptarse a una nueva época y de fomentar el periodismo católico ${ }^{1}$. A partir de 1868 , abundan sermones, pastorales, folletos que explican la importancia de la prensa católica para la defensa de los intereses religiosos:

Aunque sabemos que la salvación de los pueblos debe venir con la palabra evangélica [...] tampoco desconocemos que allí donde no puede llegar la palabra del sacerdote, bien sea porque unos cierren los oídos para no escucharla rehuyéndose acudir al templo santo, o bien sea porque el frío de la indiferencia y de la incredulidad se vaya apoderando progresivamente de otros, es de todo punto necesario lo

1. León XIII recalcó en varias encíclicas la necesidad de fomentar el periodismo católico y de "contraponer escrito a escrito, a fin de que el mismo medio que tanto puede para la ruina se trueque en salvación y beneficio de los mortales". Encíclica del 15 de febrero de 1882 al Episcopado italiano. 
hagamos llegar por medio de la imprenta para que ésta trasmita en alas del vapor la verdad hasta el último rincón donde el error tiene sus guaridas ${ }^{2}$.

La irrupción y el extraordinario crecimiento del impreso así como la aparición de comportamientos sociales nuevos con respecto a la lectura y a la información son temas de honda preocupación para la Iglesia española. En 1871, el eclesiástico integrista Sardá y Salvany, periodista y director de la Revista Popular, reconoce que se está produciendo una revolución en el campo de la comunicación social y que la situación privilegiada de la Iglesia que, hasta entonces, le había permitido controlar el acceso a la información, estaba amenazada:

Pero el hecho público e innegable es que se lee, y se lee sin descanso. La prensa no cesa de dar a la voracidad de los pueblos, libro tras libro, hoja tras hoja, periódico tras periódico. La prensa es, pues, la reina del siglo ${ }^{3}$.

Sin abandonar su visceral desconfianza con respecto a todo lo impreso, la Iglesia reacciona ante las nuevas realidades de la comunicación social y preconiza nuevos comportamientos, nuevas tácticas.

Cabe señalar que las estrategias elaboradas por la Iglesia en materia de comunicación social no se desarrollan de manera lineal en el tiempo. De 1868 a 1875 , se trata ante todo de un comportamiento defensivo que desemboca en una verdadera táctica militante. Surgen en aquel momento los primeros conatos de organización de la prensa católica que cuenta con el respaldo activo de numerosas asociaciones de católicos.

En aquel período, a pesar de la incipiente ruptura entre las publicaciones tradiconalistas y otras publicaciones católicas que rechazan el hermetismo doctrinal y el apasionamiento político de carlistas e integristas, la prensa católica catalana se integra en un frente bastante homogéneo cuya tónica dominante es la defensa de los intereses religiosos frente al peligro que supone para la Iglesia la revolución de 1868.

La mayoría de las publicaciones que estudiamos ostenta la bandera de un periodismo combativo y militante. Revista católicas no políticas como la revista catalana Ecos del Amor a María, no vacilan en animar a los católicos a que se organicen para la defensa de una Iglesia en peligro:

Si en todos tiempos gravita sobre nosotros un deber indeclinable de luchar a diestra y a siniestra contra los enemigos de Dios y de las

2. Pedro de la Torre y del Pozo, O el catolicismo o nada, o sea examen de todas las religiones hoy dominantes ante el tribunal de la razón, Barcelona, Imprenta de Magriña y Subirana, 1869, p. 5

3. Félix Sardá y Salvany, Manual del Apostolado de la Prensa, Tipografía Católica, 1873. 
almas, hoy, que una guerra contínua e hipócrita [...] forcejea por arrancar a la Iglesia sus venerandos blasones y a los fieles sus más puras creencias, no podemos dejar de lanzarnos con toda fe y con toda confianza a este combate digno, que bendeciría al Señor ${ }^{4}$.

La defensa de la "verdad" frente a los embates del "error" constituye la misión primordial de la prensa católica en aquel momento. Algunas publicaciones como la Revista Popular afirman que la prensa es un campo de batalla en el que se enfrentan "los soldados de Cristo" y los enemigos de la Iglesia 5 .

Después de 1875, surgen en el campo de la prensa católica catalana, publicaciones que, como La Veu de Montserrat, El Criterio Católico o La Academia Calasancia, rechazan el periodismo meramente político o polémico y que pretenden definir, desde una vertiente más positiva y abierta a su época, la organización y el cometido del periodismo católico $0^{6}$. Varios factores explican esta evolución dentro del campo de la publicística católica. Es de señalar primero el papel del Papa León XIII, que promovió y alentó todas las iniciativas que pudiesen propiciar el desarrollo de un auténtico periodismo católico. Por otra parte, el antagonismo incipiente provocado en la prensa católica catalana por el primer conflicto entre el diario carlista La Convicción y una publicación católica mucho más moderada políticamente y atenta a los cambios de la sociedad española, El Diario de Barcelona, se exacerbó después de $1875^{7}$. Durante la Restauración y hasta finales de XIX, la desunión de los católicos y las enconadas luchas entre publicaciones tradicionalistas y las demás publicaciones católicas entorpecieron la eficacia del periodismo católico e imposibilitaron cualquier planteamiento de organización local o nacional. A este respecto es significativo notar que la primera Asamblea de la Buena Prensa, que se celebró en Sevilla en 1904, dedicó gran parte de sus sesiones a evidenciar las carencias y torpezas del periodismo católico español de finales de siglo.

4. "Al Excelentísimo Obispo de Barcelona", Ecos del Amor a María, 1868. Esta revista, que tiene una publicación quincenal y cuyo director es el eclesiástico S. Martí y Cantó, empezó a publicarse en 1867 y duró hasta 1886.

5. Esta revista, que empieza a publicarse en Barcelona en el año 1871, representa el sector integrista más combativo en aquel momento. Su director, el eclesiástico Félix Sardá y Salvany, recalca repetidas veces la misión de "guerra", de cruzada que tiene el periodismo católico: "Nuestra táctica debe ser la de un gran ejército disperso en guerrillas", Boletín Oficial del Apostolado de la Prensa, enero 1872.

6. La Academia Calasancia empieza a publicarse en Barcelona en el año 1891. Colaboran en ella eclesiásticos católicos moderados como Eduardo Llamas, que fundó El Criterio Católico en 1884. LaVeu de Montserrat, que surge en 1881, es dirigida por el eciesiástico Jaume Collell y es el portavoz de la llamada Escuela de Vich.

7. En 1871, La Convicción entabla una polémica doctrinal sobre el significado dogmático del Syllabus y acusa al Diario de Barcelona de ser católico-liberal, ya que no publica una adhesión solemne y pública al Syllabus en primera página. 
Pero pese a que, a finales del siglo XIX, la Iglesia no haya sido capaz de superar el desfase entre las exigencias de la comunicación social y sus propias estrategias o tácticas, no se pueden infravalorar los intentos de adaptación a una nueva época y los conatos de organización de un periodismo católico.

\section{La prensa militante catalana de 1868 a 1875}

El comportamiento defensivo de la Iglesia en un primer momento y la movilización que acarrea, explican en parte, el florecimiento de las publicaciones católicas de 1868 a 1874, especialmente en Cataluña. En Barcelona, de 1868 a 1875 , aparecen más de 15 nuevas publicaciones carlistas y simpatizantes del carlismo.

A pesar del carácter efímero de algunas de estas publicaciones que, como en el caso de Lo Crit de la Patria sólo publican algunos números, este extraordinario incremento de la prensa católica refleja la voluntad de la Iglesia de no quedarse al margen del profundo cambio provocado por la revolución de 1868 .

Presentamos a continuación la lista de los periódicos y revistas carlistas, integristas y otras publicaciones católicas que aparecen de 1868 hasta 1875 en Barcelona.

\section{Publicaciones carlistas}

Bien del País (El)

Bien de España (El)

Bolas de la Setmana

Convicción (La)

Crit de la Patria (Lo)

Cucurulla Roja (La)

Don Juan Tenorio

Estandarte Católico (El)

Hermitaño (El)

Honor Catalán (El)

Lealtad (La)

Macabeos (Los)

Margarita (La)

Nuevo Pelayo (El)

Revista Católica (La)

Sacristán (El)
1868

1869

1870

1870

1871

1874

1871

1871

1871

1871

1871

1868

1870

1872

1868

1870 


\title{
Publicaciones integristas
}

\author{
Almanaque de los Amigos del Papa $\quad 1872$ \\ Ecos del Vaticano $\quad 1874$ \\ Revista Popular $\quad 1871$
}

\section{Otras publicaciones católicas}

$\begin{array}{ll}\text { Almanaque de los devotos de Santa Teresa } & 1874 \\ \text { Amigo de las Almas del Papa (El) } & 1868 \\ \text { Boletín del Apostolado de la Prensa } & 1871 \\ \text { Zuavo del Papa } & 1872 \\ \text { Rosario (El) } & 1871 \\ \text { Revista Franciscana (La) } & 1873 \\ \text { Revista de las Misiones Católicas } & 1872 \\ \text { Santa Teresa de Jesús } & 1872 \\ \text { Santos Angeles (Los) } & 1873 \\ \text { Voz de España (La) } & 1869\end{array}$

Es de notar también la diversidad de la prensa de aquel período. Predominan las publicaciones carlistas pero también aparecen publicaciones marcadamente integristas com la Revista Popular y el Almanaque de los Amigos del Papa, ambas dirigidas por Félix Sardá y Salvany. También aparecen publicaciones satíricas o humorísticas. Esta prensa satírica, de tinte integrista que conoce un formidable desarrollo en Cataluña a partir de 1882, aparece como una respuesta a las publicaciones satíricas liberales del momento, entre otras, La Campana de Gracia y La Flaca.

Otra característica de la prensa católica catalana del sexenio es la colaboración cada vez más activa de los laicos y de las asociaciones católicas que intentan, por todos los medios posibles organizar y difundir las "buenas lecturas". Inspirándose en los esfuerzos acometidos por varias asociaciones francesas como la Société Saint Vicent de Paul, las asociaciones católicas españolas se convierten en nuevos circuitos de distribución de obras y publicaciones ortodoxas".

8. La Campana de Gracia empieza a publicarse en Barcelona en mayo de 1870, La Flaca en 1879. En cuanto a la prensa católica satírica cabe reseñar Lo Crit de la Patria en 1871, La Cucurrulla Roja en 1874 , cuyo tono virulento y acerbo constituye uno de los primeros ejemplos de la prensa católica humorística y satírica que florece a partir de 1880. Citemos Lo Burinot, 1880, La Vespa, 1882, L'Avi Vell, 1882, Lo Bon Cristiá, 1883, Lo Fuet, 1883, Lo Mestre Titas, 1888, L'Espurna, 1888 y La Llagosta, 1888.

En su estudio de la prensa carlista de 1868 a 1876, Vicente Garmendia cita periódicos carlistas humorísticos de Madrid que se publican en el sexenio, como La Gorda o El Papelito. "Notas para un estudio de la prensa carlista, 1868-1876", en Prensa y Sociedad en España (1820-1936), Madrid, Cuadernos para el Diálogo, 1975.

9. La Société Saint Vincent de Paul publica, a partir de 1851 , revistas y periódicos católicos como Les Petites Lectures, almanaques y obras edificantes. 
La completa libertad de prensa que trajo consigo la revolución permitió a los católicos tomar una serie de iniciativas en materia de prensa que fueron apoyadas tanto por la jerarquía católica como por las distintas asociaciones católicas que se organizaron a partir de 1869 .

El auge y la militancia de la prensa católica catalana patentes desde 1868 pueden explicarse en parte por el papel desempeñado por distintas asociaciones como La Asociación de Católicos, La Juventud Católica o la Pía Unión de San Miguel Arcángel ${ }^{10}$.

El mismo Sardá y Salvany afirma la necesidad de asociar todos los católicos a un esfuerzo común, por medio de apostolados u otras estructuras colectivas, y, en 1871, para justificar el Apostolado de la Prensa, escribe que es necesario:

Dar unidad a estos esfuerzos, darles pensamiento común, movimiento unánime, sin perjuicio de la necesaria libertad de acción en cada grupo ${ }^{11}$.

Como ya apuntamos, conviene matizar cuál será la línea evolutiva de la prensa católica catalana de 1868 a 1900. En un primer período, de 1868 a 1875 , la gran mayoría de las publicaciones catalanas reflejan, pese a opciones políticas distintas, la postura defensiva de la Iglesia. Frente al nuevo poder civil establecido, el conjunto de la prensa de aquel período puede caracterizarse por un lenguaje eminentemente combativo y por su finalidad de proselitismo. Esta relativa homogeneidad no debe, sin embargo, ocultar la pugna ya existente entre algunos diarios más moderados como el Diario de Barcelona y otras publicaciones cuya militancia apunta hacia posturas meramente defensivas ${ }^{12}$. Pero una característica común de la prensa católica de 1868 a 1875 es su preocupación, reiteradamente expresada, por definir y organizar un periodismo católico capaz de competir con la prensa liberal. La mayoría de las publicaciones católicas del sexenio dedican un sinfín de

10. La junta directiva de la Asociación de Católicos se organizó en diciembre de 1868, en Madrid, bajo la tutela del Marqués de Viluma. En 1869, Barcelona cuenta también con la misma asociación. En cuanto a La Juventud Católica, se estableció en Barcelona en 1870 y se extendió en seguida a varias provincias catalanas. En 1878, existían academias de La Juventud Católica en Gerona, Solsona, Manresa, Sabadell, Berga y Manlleu. Es de notar que el presidente de la academia de Barcelona, José de Palau y Huguet, era director de la conocida revista integrista Dogma y Razón. que empezó a publicarse en 1887. En La Asociación de Católicos de Barcelona desempeña un papel importante el periodista integrista José Coll y Vehí, colaborador del Correo Catalán.

11. Sardá y Salvany, Boletín oficial del apostolado de la prensa, Barcelona, Tipografía Católica, enero de 1872.

12. El Diario de Barcelona, dirigido en aquel período por Juan Mañé y Flaquer, católico conservador, moderado en sus posturas, que se enfrenta, después de 1875, con la prensa carlista e integrista. Este enfrentamiento es particularmente violento en 1881 cuando Mañé y Flaquer elogia, aunque prudentemente, la Unión Católica de Pidal. 
artículos a la definición de un periodismo auténticamente católico, capaz de regirse por sus propias reglas y de enfrentarse con la pujante empresa de la prensa liberal ${ }^{13}$.

Este planteamiento de una militancia combativa por parte de la Iglesia, que tiene que expresarse principalmente en la prensa, es uno de los temas claves del momento. Muy pocas son las revistas que no dedican un espacio preferente al tema de la prensa católica como nueva arma de combate. Revistas católicas moderadas como La Familia Cristiana o la Ciencia Católica, que pretenden ser meramente predicativas o informativas, intentan definir la misión de la prensa católica e insisten sobre la necesidad de nuevas modalidades de acción por parte de los católicos ${ }^{14}$. La revista $E \cos$ de Amor a María llama los católicos a un "combate", a una "cruzada"15.

En el Manual del Apostolado de la Prensa, en 1873, Sardá y Salvany afirma que la imprenta:

Es el principal campo de batalla de hoy, acudamos a él todos los buenos.

Indudablemente, dentro de la publicística católica catalana, las publicaciones que más talante defensivo ostentaron fueron las carlistas e integristas. Publicaciones como el periódico La Convicción dirigido por el carlista Luis María de Llauder y la Revista Popular, cuyo director iba a ser uno de los jefes de fila del integrismo catalán, no se limitaban a ser meros divulgadores de noticias políticas. Llegaron a ser verdaderas tribunas desde las cuales personalidades católicas relevantes de la época pretendieron organizar un periodismo combativo. En el contexto defensivo del sexenio, también quisieron organizar activamente las masas católicas y sus directores

13. Numerosos laicos católicos, y eclesiásticos dedican opúsculos, sermones o artículos en la prensa a esta cuestión. En Barcelona, los eclesiásticos más activos son Idelfonso Gatell, Eduardo Vilarrasa y Félix Sardá y Salvany. También cabe subrayar el papel de la jerarquía católica. El Obispo Pantaleón Montserrat apoya la creación del Apostolado de la Prensa en 1871. En otro artículo tendremos ocasión de analizar el papel de eclesiásticos catalanes tan conocidos como Eduardo Llanas, director de El Criterio Católico desde 1884, de Jaume Collell y de Torras y Bages. Estas iniciativas se extienden hasta finales del siglo XIX. En 1876, el Arzobispo de Barcelona funda la Revista Cristiana.

14. La Familia Cristiana que empieza a publicarse en 1876 , anuncia que está decidida a "combatir, pues, la negación de creencias que embrutece al hombre: [...] aquélla es la misión que ha de desempeñar la prensa religiosa y que a aquel objetivo responde la misión que se han impuesto los redactores de $L a$ Familia Cristiana".

Es interesante notar que, incluso revistas católicas como la Ciencia Católica, de publicación más tardía, que se pretenden alejadas de todo compromiso político y que quieren ser informativas, dedican mucho espacio al papel militante de la prensa católica. Esta revista mensual publicada bajo los auspicios del Obispo José María de Urquinaona salió a la luz en diciembre de 1881.

15. Esta revista quincenal es dirigida por el eclesiástico Martí y Cantó que colaboró, a partir de 1890 , en el Boletín de la Obra de Buenas Lecturas. 
aparecían como jefes espirituales y morales ${ }^{16}$. Prueba de ello es el papel desempeñado por la Revista Popular en la organización de las primeras grandes peregrinaciones católicas a partir de 1876. Desde los primeros números, esta misma revista incita sus lectores a "manifestarse" a favor de Pío IX enviando limosnas para el "Papa pobre" 1 ?

Con la publicación de estos periódicos y revistas, como más tarde con La Hormiga de Oro en 1884 y la revista integrista Dogma y Razón en 1887 , surge un debate que habrá de durar hasta finales del siglo, sobre los nuevos cometidos de la prensa católica.

A partir de 1870 , dos publicaciones católicas catalanas promueven una verdadera campaña de movilización de los católicos. La Convicción, que tiene dos ediciones diarias, publica numerosos artículos del carlista Luis María de Llauder dedicados a las circunstancias políticas del momento ${ }^{18}$.

Pero, es sobre todo la Revista Popular la que mejor refleja las preocupaciones de los católicos y de la Iglesia por organizar un periodismo militante ${ }^{19}$.

Esta revista semanal, que declara querer estar al alcance de todos y se preocupa por tener una forma más amena y atractiva, dedica muchos editoriales a caracterizar la buena y la mala prensa ${ }^{20}$. Su director, el eclesiástico integrista Sardá y Salvany, personalidad católica relevante dentro de la historia religiosa catalana del siglo XIX, promueve otras publicaciones ca-

16. En su trabajo La cuestión religiosa en la Restauración, Santander, Soc. Menéndez Pelayo, 1984, Marta Campomar Fornieles subraya, al analizar el periódico católico de Nocedal, El Siglo Futuro, las características de la prensa católica del siglo XIX y. recalca la contribución de la mayor parte de las publicaciones católicas, y especialmente tradicionalistas, a la organización religiosa y política de las masas católicas.

17. A partir de su publicación, la Revista Popular constituye una verdadera plataforma desde la que se organizan las principales manifestaciones religiosas para movilizar a los católicos: misas colectivas, peregrinaciones, celebración de varios centenarios. Esta publicación permitirá al integrismo, que no está representado por ningún partido, disponer desde 1875 hasta 1888 de un formidable instrumento de presión político e ideológico.

18. La Convicción sólo se publicó hasta el año 1873 y fue sustituido por el Correo Catalán. La Convicción incluye una "crónica local", una "crónica religiosa", un "correo nacional", un "correo extranjero" $y$, en la edición de la tarde, una "sección política" a cargo de Llauder. Cabe subrayar la gran vitalidad de la prensa carlista en Barcelona, donde se publican el Correo Catalún, 1876, y a partir de 1884 La Hormiga de Oro, también dirigida por Llauder. En 1880-1881 el Correo Catalán era el periódico católico barcelonés que más importante tirada tenía después del Diario de Barcelona. Los derechos de timbre eran de 1534,49 pesetas. Citado por Pere Voltes i Bou en Barcelona y la seva premsa al segle XIX. Barcelona, Asociación de la Prensa, 1977.

19. En una serie de artículos publicados bajo el título "Los malos periódicos" y "El peor de nuestros males" desde el año 1871, Sardá y Salvany define la nueva prensa católica.

20. En el año 1872, la Revista Popular alcanzaba una tirada de 30.000 ejemplares. Esta revista, que llegó a publicarse hasta 1928, contaba con la colaboración de personalidades católicas importantes: el jesuitas Celestí Matas, amigo íntimo de Salvany, autor de las cartas : "Al obrero católico"; Milá i Fontanals, que firmaba las "parábolas de Krummacher". Antes de lanzar esta revista en 1871, Sardá y 
tólicas como el Almanaque de los Amigos del Papa y Los Ecos del Vaticano ${ }^{21}$.

Desde los primeros días, la Revista Popular se dedica a proponer un verdadero plan de campaña contra la mala prensa, "ese enemigo doméstico, silencioso autor de la mayor parte de los desastres morales que lamentamos en la patria y en la familia"22.

Ateniéndose a la línea defensiva de la mayor parte de las publicaciones católicas que surgen en el sexenio, la Revista Popular anima a todos los fieles a que ostenten un comportamiento combativo.

Para justificar la nueva estrategia defensiva de la Iglesia, Salvany explica que la religión y las circunstancias políticas son indisociables y compara España con un nuevo campo de batalla en el que "venimos a lidiar y en el que somos intolerantes como la verdad, intransigentes como el deber" 23 .

En el primer número de esta revista, Sardá y Salvany define su contenido con el lema: "nada, ni un pensamiento para la política". No se trata para la revista de identificarse con partido político alguno. Pero si la política se mete con la religión y amenaza sus cimientos, entonces:

Defenderemos nuestro puesto hasta donde sea posible a nuestras fuerzas la defensa; sostendremos con brío el ataque; procuraremos rechazar de nuestro terreno los enemigos ${ }^{24 .}$

Para este eclesiástico, el nuevo contexto político del sexenio recuerda épocas pasadas en la historia de la Iglesia en las que eran necesarias verdaderas cruzadas religiosas. En otros artículos, Salvany defiende lo que llama "el derecho a la insurrección". No se trata de incitar a los católicos a tomar las armas pero deben ser tan inflexibles como los primeros católicos, como el Apóstol San Pedro que no vaciló en rebelarse contra las autoridades civiles romanas ${ }^{25}$.

Salvany había publicado, a partir de 1869 , una serie de opúsculos, Propaganda Católica, en los que colaboraron los mismos que vueiven a encontrarse más tarde en la Revista Popular. Sardá y Salvany colaboró al principio de su publicación, de manera anónima en el Correo Catalán. Empezó a publicar, por partes, El liberalismo es pecado en 1884, en La Hormiga de Oro.

21. El Almanaque de los Amigos del Papa, publicado en 1872 hasta 1928, reivindica su finalidad de propaganda político-religiosa y refleja la devoción y la adhesión del sector tradicionalista a Pío IX: "Más que un almanaque es éste un libro de propaganda y de lucha destinado a popularizar y fomentar en la familia española el amor a nuestro inmortal Pontífice".

22. "Los malos periódicos", Revista Popular, 25 marzo 1871.

23. "La política y la religión", Revista Popular, 1 de enero 1871.

24. "La política y la religión", Rerista Popular, I de enero 1871.

25. "La cuestión no es aquí de cañones ni de fusiles, que no los conocieron los Apóstoles y la Revista no se ocupa de eso. Pero en el terreno de la defensa y del ataque morales, en el terreno de la lucha pacífica que es la nuestra, la fiesta de hoy bien claro nos muestra nuestros deberes".

"Recuerdos oportunos", Revista Popular, 18 mayo 1872. 
A pesar del tono prudente de Sardá y Salvany en los primeros años de publicación de la revista, ya trasluce la ideología integrista de su director, la cual perdurará hasta 1896 . Este lenguaje de guerra, combativo e inflexible, se encuentra en la mayoría de las publicaciones católicas de Barcelona hasta 1875 . Ello se explica, como ya dijimos, por la postura defensiva de la Iglesia en el período revolucionario pero también por el fuerte arraigo en Cataluña del carlismo y del integrismo.

Un ejemplo significativo del carácter radical y militante de algunas publicaciones es el caso de la revista Lo Crit de la Patria, que empieza a publicarse en 1871. Esta revista, que se adhirió al principio al carlismo, evoluciona a lo largo de los años hasta posturas claramente integristas y proclama, desde el inicio de su publicación, su compromiso de revista militante ${ }^{26}$.

Sin embargo, el carácter defensivo e ideológicamente militante de estas publicaciones no debe ocultar sus aspecto más originales en el campo de la prensa. Nos referimos a la voluntad de publicaciones como la Revista Popular por adaptarse a las nuevas exigencias en materia de periodismo. Con una sección de variedades, una sección bibliográfica exhaustiva y la publicación de novelas edificantes, la Revista Popular intenta amenizar sus artículos y captar un nuevo público ${ }^{27}$. La Revista Popular publica artículos de fondo sobre temas candentes bajo la forma de diálogos que le confieren un carácter más ameno y familiar; en el prospecto, Sardá y Salvany insiste sobre la finalidad de la revista que es captar un público más amplio, menos "culto". Este esfuerzo por captar nuevos públicos y competir con la prensa liberal es patente en publicaciones católicas ulteriores. Citemos el caso evidente de La Hormiga de Oro, que incluye una sección de variedades y de literatura y que pretende ser "una Ilustración como las demás"28.

Otro aspecto nuevo es el esfuerzo por incluir en estas publicaciones grabados que puedan atraer al lector y amenizar el carácter serio o doctrinal. Esto es particularmente patente en La Hormiga de Oro, que presenta grabados variados y de calidad muy cuidada ${ }^{29}$.

26. "Nuestro carácter especial es la franqueza, y con esta misma franqueza diremos a todos los que quieren escucharnos: fuera trampas, fuera liberalismo, fuera partidos, fuera mentiras y fuera palabras". Lo Crit de la Patria, 25 noviembre 1871.

Esta revista publicada en catalắn sólo publica un número en 1871. Reanuda su publicación en 1883, año en el que ostenta sus simpatías por Cándido Nocedal y, en 1888 se adhiere al integrismo.

27. La Revista Popular publica lo que llama "literatura amena y edificante". Se trata de traducciones de Mathilde de Bourbon, cuyas novelas rosas y católicas se estilan mucho en España en la prensa católica, traducciones de Paul Féval, Veuillot y trozos de obras conocidas de Polo y Peyrolón, del padre Franco, etc...

28. "Reconociendo la necesidad de hacer frente a la influencia dañina que ejercen en el seno de las familias y de la juventud la multitud de periódicos e ilustraciones racionalistas, de moral relajada y fomentadoras del materialismo y descreimiento modernos [...] fundamos esta Revista ilustrada".

"Saludos", La Hormiga de Oro, enero 1893.

29. Dedicamos un estudio a La Hormiga de Oro en "La presse traditionaliste face à la littérature. La Hormiga de Oro", en Typologie de la Presse Hispanique, Rennes, Universidad, 1984. 
A pesar de las preocupaciones reflejadas en esta prensa catalana por captar nuevos públicos, por competir con grandes editoriales liberales, la mayoría de los periódicos y de las revistas católicos que se publican entonces se limitan muchas veces a ser una prolongación del magisterio eclesiástico. Más que un órgano de información, la prensa católica se ajusta muchas veces a lo que podríamos llamar un periodismo doctrinal. Por otra parte, la confusión entre política y religión que caracteriza la mayoría de la publicaciones tradicionalistas no permite a la prensa católica organizarse de manera duradera.

A partir de 1875 , este periodismo combativo y polémico desemboca en un antagonismo ideológico, exacerbado por actitudes políticas. En el panorama de la prensa católica catalana de fines del siglo, se destaca la lucha enconada entre muchas publicaciones católicas, que esteriliza y neutraliza la defensa de los intereses religiosos e impide que se organice la prensa católica a escala nacional ${ }^{30}$.

La nueva concepción de la prensa católica que se va forjando en la segunda mitad del siglo XIX desemboca también en varias iniciativas católicas para organizar asociaciones de defensa y de propaganda de la buena prensa.

\section{Asociaciones de defensa y propaganda}

En Barcelona, uno de los primeros esfuerzos para llevar a cabo una organización local y nacional de la prensa católica se plasma en la creación en 1871 de una asociación llamada el Apostolado de la Prensa. Promovida por el Obispo de Barcelona, Pantaleón Montserrat, esta asociación cuenta con la colaboración de personalidades católicas destacadas. Es de mencionar la activa colaboración de Sardá y Salvany, miembro de la junta general pero también uno de los periodistas que más intervino en la elaboración de los estatutos del Apostolado y en el boletín de la asociación. También conviene señalar la presencia de Salvador Casañas, Obispo de Urgel, de Idelfonso Gatell, que fue también activo colaborador de la Obra de Buenas Lecturas, de la que hablaremos más tarde.

Como en muchas asociaciones católicas posteriores, la jerarquía católica desempeña un papel importante pero, y es un hecho nuevo, la participación de laicos católicos es cada vez más significativa.

30. José Manuel de Bernardo Ares, en su análisis de la prensa católica valenciana en la última década del siglo XIX, pone de relieve el carácter marcadamente político de muchas publicaciones católicas y sus repercusiones en la prensa católica en general. Se refiere a ello en el capítulo primero de su estudio Ideologías y opciones políticas a través de la prensa a finales del siglo XIX, Córdoba, Imprenta Provincial, 1981. 
Las sociedades de buenas obras, de buenas lecturas, los círculos católicos forman una red que tiene por finalidad fomentar las iniciativas colectivas por parte de los católicos. Estas primeras experiencias de asociacionismo católico se inspiran en los esfuerzos acometidos en el mismo período en otros países europeos.

En Francia numerosas experiencias se llevan a cabo desde 1870. En enero de 1870, algunos eclesiásticos franceses como el padre Alzon quieren crear una asociación que agruparía a católicos de otros países para fomentar una especie de Liga católica internacional ${ }^{31}$.

En 1871, en España, el Apostolado de la Prensa recomienda lo mismo. Las libertades de expresión y de asociación que trajo consigo la revolución de 1868 permitieron que se realizasen los primeros movimientos católicos asociativos importantes. Reprimida en otros sectores, la Iglesia española se aprovecha de estos nuevos derechos y como afirma el mismo Sardá y Salvany:

Los católicos hemos de asociarnos en todo para todo. ¿Qué es en suma la Iglesia sino una vastísima asociación que cobija y da vida a una porción de asociaciones? ? $^{32}$

El primer número del Boletín Oficial del Apostolado de la Prensa define el nuevo cometido de la prensa católica en un contexto de militancia religiosa. Sardá y Salvany recurre a imágenes relacionadas con la estrategia de guerra para caracterizar una organización que debe competir con la prensa revolucionaria: "nuestra táctica debe ser la de un gran ejército disperso en guerrillas" 33 .

El obispo de Barcelona, al presentar èl proyecto de este apostolado, insiste sobre la necesidad perentoria para la Iglesia de acudir a nuevos medios de control de las ideas y de las conciencias:

El Señor ha querido que se ejerza una especie de Apostolado por la propaganda de buenos libros, ya que el de la predicación se mira con tanta indiferencia por los que, en el hecho de saber leer, creen que no necesitan oír sermones ${ }^{34}$.

Por primera vez en la prensa católica del siglo XIX, los mismos católicos lamentan la falta de vitalidad y organización del periodismo católico y

31. Esta liga sería "Una asociación de oraciones, de limosnas, de acciones, de escuelas pías, de misiones y de difusión de la fe". Citado por Pierre Pierrard en su obra L'Eglise et les ouvriers en France, 1840-1940, Paris, Hachette, 1984, p. 289.

32. Sardá y Salvany, “¿Qué exigen las circunstancias?”, Revista Popular, 14 junio 1873.

33. Sardá y Salvany, Boletín Oficial del Apostolado de la Prensa, enero de 1872, p. 2.

34. Carta del Excelentísimo Pantaleón Montserrat a Primitivo Sanmartí,Boletín Oficial del Apostolado de la Prensa, $\mathrm{n}^{\circ} 1$, enero de 1872 , p. 2. 
se esfuerzan por adaptarlo a las nuevas exigencias de comunicación social $^{35}$.

Desde sus inicios, esta asociación se presenta bajo la forma de una federación de centros de difusión de buenas lecturas y, sobre todo, de propaganda. Esta propagación de las "buenas lecturas" debe hacerse por todos los medios posibles: creación de bibliotecas, distribución de hojas sueltas, impresos y opúsculos en todas las parroquias ${ }^{36}$.

En cada diócesis, una junta diocesana dirige las actividades del apostolado y cada parroquia también cuenta con una junta parroquial. Estas juntas, generalmente dirigidas por eclesiásticos, colaboraban con otras asociaciones católicas como, por ejemplo, en Barcelona, con la Juventud Católica creada en 1871. En 1871, Barcelona contaba con 13 juntas diocesanas; en algunas de ellas participaban personalidades católicas conocidas por sus posturas radicales e intransigentes como Salvador Casañas, o el eclesiástico Primitivo Sanmartí.

Por otra parte, el Apostolado de la Prensa permitió crear una verdadera red de enlace entre editoriales y librerías católicas y las distintas juntas diocesanas y parroquiales ${ }^{37}$.

Así pues, editores católicos como Olamendi en Madrid o Subirana en Barcelona distribuyen obras de la Biblioteca Popular a las bibliotecas de las diócesis y parroquias que pertenecen al Apostolado de la Prensa. Los vínculos entre editores y librerías católicas con la jerarquía católica y el clero son estrechos; son vínculos a la vez financieros, comerciales e ideológi$\cos ^{38}$.

35. Sánchez Isidro, en su estudio "La Iglesia española y el desarrollo de la Buena prensa", alude al desarrollo de la prensa católica española en el siglo XIX y menciona los primeros esfuerzos que se hicieron desde 1836 para fomentar el periodismo católico. Creemos, sin embargo, que habrá que esperar a la segunda mitad del siglo XIX para que cuajen de manera duradera los primeros intentos de organización local y nacional de la prensa católica. En la primera mitad del siglo, varios católicos habían denunciado las carencias de la prensa católica, Donoso Cortés, en una carta dirigida al Conde de Montalambert el 26 de mayo 1849 decía: "En cuanto a la manera de combatir, no encuentro más que una pueda dar provechosos resultados: el combate por medio de la prensa periódica".

36. "Por medio de esta organización, que la junta diocesana de Tortosa ha llamado muy bien federativa, podemos tender sobre el suelo de la patria una verdadera red de propaganda que la cubra toda". Boletín Oficial del Apostolado de la Prensa, p. 2.

37. "La Biblioteca parroquial debe ser una sucursal de todas las librerías religiosas de España, el conducto por donde vayan a parar a manos del pueblo desde la más oscura novena o devocionario que pide una mujer, hasta la obra de alta polémica que solicite el letrado", ibíd., p. 5.

38. Este aspecto de la comunicación impresa ha sido analizado por Jean-Francois Botrel en su estudio: "L'Eglise et la communication imprimée: doctrine et pratiques", Metodología de la historia de la prensa española, Madrid, Siglo XXI, 1982.

Conviene mencionar la existencia en Barcelona de una Biblioteca Popular, también promovida por Pantaleón Montserrat en los años 1869-1870 y que colabora con la Tipografía Católica, calle del Pino, 5. Esta biblioteca, mencionada en el Manual del Apostolado de la Prensa, distribuye "dos o tres libros cada mes sólo por cuatro pesetas al año en España". 
Esta verdadera militancia religiosa en materia de prensa y de las buenas lecturas se inspira en la obra de buenas lecturas o Oeuvre des Bons Livres, fundada en Cambrai en 1820 , y cuya meta era crear bibliotecas católicas, o depósitos de "buenos libros" que se prestaban gratuitamente a los fieles".

Por otra parte, en 1873 , en el momento que Sardá y Salvany redacta el Manual del Apostolado de la Prensa, él estaba al corriente de las iniciativas francesas en materia de prensa católica y conocía La Maison de la Bonne Presse fundada en París en aquella época por los padres agustinos ${ }^{40}$.

En esta asociación francesa, existía un grupo de eclesiásticos, verdaderos militantes de la buena prensa, como los canónigos Janvier y Gerbier y los abates Poulin y Thellier de Poncheville, que fomentaron varios apostolados de la buena prensa en Francia. También cabe mencionar la organización parroquial del abate Wallez, que tenía por finalidad evangelizar a las familias cristianas mediante la prensa. Todas estas obras o apostolados proponían a los fieles un comportamiento nuevo, más combativo y adaptado a su época, y el éxito de estas experiencias en el campo del periodismo católico constituyó indudablemente un modelo para los católicos españoles ${ }^{41}$.

El Apostolado de la Prensa dispone de otros medios para difundir la buena prensa y las sanas lecturas. Se convocan certámenes literarios organizados por la junta diocesana de Barcelona y en los que pueden participar todos los fieles. Estos certámenes convocados cada semestre proponen en su convocatoria temas como "La religión católica, única verdadera", "La Internacional y la Iglesia" o "Los enemigos del alma", que deben permitir a escritores católicos competir con obras "de dudosa moralidad". Estas contraofensivas en materia de publicaciones también incluyen otras formas de propaganda como, por ejemplo, los certámenes antiprotestantes en los que se otorga un premio al "que acreditase haber entregado a su respectiva autoridad eclesiástica mayor número de libros protestantes"42.

39 A principios del siglo XIX varios depósitos de "buenas lecturas" fueron creados en Francia. Cabe mencionar el caso de Limoges donde se fundó en 1833 bajo la iniciativa del clero una de las primeras Oeuvres des Bons Livres. El fundador de esta obra, el padre Rousier, escribe: "Je cédais à une double conviction: j'étais intimement persuadé que la lecture est un des besoins de la societé actuelle, et que la religion et les bonnes moeurs ont beaucoup à craindre ou à espérer selon la direction qui leur est donnée". Bibliographie Catholique, Tome II, 1842-1843, Paris, Bureau de la Bibliographie Catholique.

40. La Maison de la Bonne Presse difundía publicaciones católicas como La Croix, Le Pélerin, Les Contemporains y contaba con un millón de suscriptores en 1890. La Obra de Buenas Lecturas de Barcelona hace muchas referencias a esta asociación francesa en su boletín del año 1899.

41. Tenemos un testimonio del interés de los católicos españoles por las iniciativas de los católicos franceses en materia de prensa en la obra de un escritor y periodista catalán, Sicars y Salvado. En su obra Misión del periodista católico en nuestros días, Barcelona, Tipografía Católica, 1909, este escritor, que colabora en el Semanario Católico de Reus, proporciona datos exhaustivos e interesantes acerca de publicaciones católicas francesas como Le Pélerin, 1873, y La Croix, 1880.

42. Boletín del Apostolado de la Prensa, enero de 1872, p. 14. El comportamiento inquisitorial recomendado en este Boletín a todos los fieles debe fomentarse también en los niños, ya que "los niños de las escuelas pueden ser excelente medio para ayudar a esta obra". 
El Boletín del Apostolado de la Prensa, publicado cada trimestre, comunica el nombre de los agraciados ganadores de una rosa de oro, como por ejemplo:

Fernando Verdera, maestro de instrucción primaria en la Barceloneta, quien puso su joya a los pies de la Patrona la Virgen del Carmen en gratitud por muchos beneficios recibidos ${ }^{43}$.

El cometido del Apostolado de la Prensa es mucho más que la simple organización de la prensa católica. Como muchas asociaciones católicas de aquel momento, este apostolado pretende encauzar y controlar a los fieles.

A este respecto es significativo fijarse en el manual del apostolado redactado por Félix Sardá y Salvany y cuyo título, Guía práctica del individuo de esta sociedad, no deja lugar a dudas en cuanto a su finalidad didáctica. Se trata de un auténtico código de conducta del buen católico que se propone a los fieles perturbados por la creciente secularización de la sociedad y que no saben cómo participar en la campaña de propaganda y militancia católica iniciada por la Iglesia.

Este manual propone una moral activa que va desde la oración a la colecta de fondos, pasando por el comportamiento inquisitorial.

Una de las maneras de practicar el militantismo católico, afirma Sardá y Salvany, es mediante la difusión de la buena prensa, y para ello hay que valerse de todos los medios:

No seáis escasos en derramar por todas partes el papel católico. Repartidlo con profusión, servios de él hasta para vuestros envoltorios [...] Reproducid en impresiones abundantes y económicas los artículos más notables que sobre la cuestión del día publique la prensa verdaderamente católica. Llevadlos siempre en abundancia en vuestra faltriquera, y al suscitarse sobre aquel punto la conversación, decid con llaneza: Pues, señor, precisamente ahi traigo un artículo en que se trata la cuestión de un modo que no deja lugar a réplica ${ }^{44}$.

Los premios otorgados en los certámenes, la distribución de obras pías en las escuelas, la difusión de periódicos y hojas sueltas en las fábricas y talleres o a la salida de la Iglesia constituyen algunos de los medios preconizados en este manual para fomentar la campaña de movilización a favor de la buena prensa. Las reglas de conducta que se proponen no tienen un cariz muy espiritual y son esencialmente prácticas. Se trata de un verdadero reclutamiento de los católicos a todos los niveles. Para ser un buen católico hay que conformarse con dogmas y preceptos. El manual del apostolado

43. Ibid., p. 14.

44. Manual del Apostolado de la Prensa, o Guía práctica del individuo de esta sociedad, Barcelona, Tipografía Católica, 1873, p. 39. 
hasta propone modelos de oraciones para difundir la buena prensa ${ }^{45}$. En dos capítulos titulados "Del Celo" y "De los diplomas", que son todo un programa, el manual propone a todos los "buenos" católicos una patente de ortodoxia y de sano comportamiento y explica que la propagación de la buena prensa y de las buenas lecturas constituye una militancia diaria ${ }^{46}$.

Las reglas de conducta cuidadosamente expuestas en este manual reflejan la preocupación de la Iglesia por disponer de instrumentos de control ideológico: control de las conciencias, control de los medios de difusión y de comunicación. El desarrollo de la "buena prensa" se inscribe dentro de una táctica defensiva por parte de la Iglesia. Una táctica defensiva que, en algunos momentos, tendrá que ceder el terreno a unos tímidos intentos de adaptación a las nuevas exigencias de la época que dejará el paso a iniciativas católicas individuales o colectivas para crear una infraestructura de difusión de las buenas lecturas. A este respecto, es interesante notar que el autor del Manual, Sardá y Salvany, a la vez que incita a los católicos a adoptar un comportamiento inflexible, analiza las debilidades del periodismo católico y plantea el problema material de difusión de las publicaciones católicas.

Un capítulo entero del Manual se dedica a los problemas financieros planteados por el Apostolado de la Prensa. Esta infraestructura financiera funciona mediante un sistema de recaudación de fondos y limosnas. Esta colecta de fondos está cuidadosamente organizada y supone la participación de todos los socios. Sardá y Salvany no vacila en plantear el problema material reiteradas veces y reconoce que, para llegar a ser una verdadera "empresa", el periodismo católico necesita dinero: "El dinero es el nervio de la guerra, y de consiguiente un elemento indispensable para la buena propaganda" 47 .

45. "Particularizad la aplicación de vuestras oraciones, por ejemplo: Iglesia;

Para que Dios promueva y suscite escritores católicos que combatan la impiedad y den gloria a su

Para el feliz éxito de los impresores verdaderamente católicos en sus empresas;

Para que se aumente la suscrición a los periódicos buenos y disminuya la de los malvados, que son más de los que muchos se figuran". Manual del Apostolado de la Prensa, p. 39.

46. "El socio del Apostolado recibirá al ingresar en el mismo o una cédula de agregación o diploma, en el cual al pie de la imagen de San Francisco Javier está indicado el lugar [...] y fecha de su admisión. Conserven los socios este documento [...] colóquenlo en un marco o guarnición en un lugar público de su casa [...] donde los que entraren lo vean colocado como una patente de catolicismo del dueño de ella [...] Téngase empero en mucha mayor estima el blasón de fervoroso católico y de soldado de la verdad, como debe serlo y lo es todo buen socio de nuestro Apostolado", ibíd, pp. 82-83.

47. Ibid. p. 41. Esta preocupación por el aspecto material y financiero de la prensa se expresa constantemente. A partir de 1870 , con las primeras asociaciones de fomento de la buena prensa, tanto la jerarquía católica como los laicos apuntan hacia una de las mayores debilidades de la prensa católica: su falta de organización material, la insuficiencia de una infraestructura financiera duradera.

La Hormiga de Oro, dirigida por Luis María de Llauder, dedica varios artículos a este problema. Citemos la serie de artículos "Las dos propagandas", publicados en 1884. 
El Manual del Apostolado propone una colecta de fondos y limosnas mensual o trimestral organizada por las juntas parroquiales. Para evitar que el celo financiero de algunos miembros disminuya, se propone la constitución de "coros" de cinco miembros. Es el jefe del coro el que recoge los fondos y distribuye a todos los socios el boletín del apostolado. Este boletín debe constituir "el lazo visible que una a los socios del Apostolado desparramados en toda la península española". Sale cada trimestre y consituye un medio de control de la actividad de los socios al publicar la lista de los donativos y de los méritos...

Este Apostolado de la Prensa, que es el primer esfuerzo por organizar la prensa católica en Barcelona, consituye un modelo para numerosas diócesis en el resto de España. En Madrid se funda un Apostolado de la Prensa en 1891. El mismo Boletín del Apostolado de Barcelona había publicado, en 1872 , una lista de los distintos apostolados establecidos en otras diócesis ${ }^{48}$.

La creación en 1871 del Apostolado de la Prensa constituye la primera etapa de un proceso de adaptación, por parte de la Iglesia, a nuevas exigencias en materia de comunicación social. Fue uno de los primeros eslabones de una serie de iniciativas que perduraron hasta bien entrado el siglo XX.

Mientras que los antagonismos ideológicos y políticos que se produjeron a partir de 1875 en la prensa entre las grandes tendencias, La Unión Católica y los tradicionalistas y luego entre carlistas e integristas, esterilizaron muchas iniciativas para estructurar el periodismo católico, las asociaciones de fomento de la prensa católica siguieron desempeñando su papel ${ }^{49}$.

En el Boletín de la Obra de Buenas Lecturas de 1899, Ildefonso Gatell, escritor católico, lamenta la falta de medios del periodismo católico. En su obra Los periódicos en la sociedad, publicada por LaHormiga de Oro en 1913, Francisco Nabot y Tomás propone varios medios para convertir el periodismo católico en una "empresa mercantil". No podemos dejar de señalar la importante serie de artículos publicados en La Academia Calasancia en los años 1890 y 1891 por Eduardo Llanas, serie que se titula "Cartas al joven Conrado sobre el periodismo católico" y que denuncia las carencias materiales de la mayor parte de las publicaciones católicas.

El mejor testimonio de las preocupaciones de la Iglesia por un aspecto nuevo de la prensa, el de su organización material y profesional, está contenido en las propuestas de la Asamblea de la Buena Prensa de Sevilla de 1904, que dicen, entre otras cosas: "Mejorar las condiciones materiales del periodista católica a fin de que su trabajo tenga el correspondiente estímulo y puede dedicarse a él con más desembarazo". Boletín de la Obra de Buenas Lecturas, año 1904, p. 78.

48. Citemos los de Vich, Valladolid, Badajoz, Avila, Barbastro. En Salamanca, el Obispo Lluch y Garriga promovió en 1871 la creación de La Sagrada Alianza, cuya finalidad era "conservar, defender y propagar la santa fe católica por medio [...] de la oración, el buen ejemplo, la palabra y la imprenta". En Granada, La Asociación del Bien, fundada en 1872, tiene finalidades parecidas a las del Apostolado de la Prensa de Barcelona.

49. El escritor católico catalán Joaquín Rubio y Ors, perteneciente al sector católico moderado representado en Cataluña por católicos procedentes de la Escuela de Vich como Eduardo Llanas o Jaime Collell, al analizar la falta de un auténtico periodismo católico subraya que "el periodismo, por efecto de aquellas divisiones, dejo de cumplir en parte, o cumplió más bien en daño que en provecho de la Iglesia, y antes en desprestigio que en honra propia, la misión que le estaba encomendada". En De la moderación en las controversias, Barcelona, Imprenta de la Casa Padre de la Caridad, 1885, p. 15. 
Como instituciones bajo el control de la jerarquía católica se mantuvieron más al margen de las contiendas político-religiosas. En Barcelona, el obispo José María Urquinaona, el arzobispo de Vich, Morgades y el de Tarragona, Benito Vilamitjana, que eran católicos moderados y estaban plenamente conformes con las nuevas orientaciones de León XIII, se esforzaron por mantener las asociaciones católicas en general al margen de los violentos enfrentamientos producidos por la desunión de los católicos ${ }^{50}$.

Indudablemente algunas de estas asociaciones reflejaron hasta cierto punto las opciones de sus miembros. Ése fue el caso del Apostolado de la Prensa de 1871, en el que desempeñaba un papel importante Sardá y Salvany. Pero otras, como la Obra de Buenas Lecturas que vio la luz en 1890 , contó con la colaboración de personalidades católicas muy diferentes y desempeñó hasta el año 1912 una labor importante en materia de organización y de difusión de la prensa católica.

Por ello quisiéramos, aunque muy brevemente, reseñar las actividades de esta asociación así como las de otras que participaron en la estrategia militante de la Iglesia en materia de prensa. Dichas asociaciones representan las distintas etapas de un proceso evolutivo que culmina con la Asamblea General de la Buena Prensa en Sevilla, en 1904. Un proceso que podríamos caracterizar como de toma de conciencia de las necesidades de la prensa católica y de reajuste y adaptación a un entorno político y social nuevo.

Otra iniciativa importante en materia de organización de la prensa católica y cuya meta se ajusta también a una estratega militante por parte de la Iglesia es la fundación, en 1890, de la Obra de Buenas Lecturas. Estaba constituida por una junta de la que formaban parte varios laicos católicos y un sacerdote, en calidad de delegado del obispo diocesano. En ella encontramos personalidades católicas relevantes de la época, como el eclesiástico Ildefonso Gatell, presidente de la Obra y fundador de la Biblioteca Parroquial de Santa Ana ${ }^{51}$.

Esta Obra actuó al principio como un verdadero centro de difusión de buenas lecturas y de algunas publicaciones católicas entre las cuales La Hoja Parroquial y La Hoja Dominical tenían un fin piadoso; a partir de 1895, El Amigo del Obrero, periódico semanal, representó una de las numerosas iniciativas por parte de la Iglesia española a finales del siglo XIX para desarrollar una prensa católica obrera ${ }^{52}$.

50. En el momento álgido de la crisis político-religiosa provocada por enfrentamientos entre el sector católico moderado, partidario de la Unión Católica, y los tradicionalistas, en 1883, el episcopado catalán prohibió la pubticación de varios periódicos tradicionalistas, entre otras publicaciones satíricas o humorísticas como Lo Burinot, L'Avi Vell, La Vespa, que habían calumniado al obispo Urquinaona y al eclesiástico Torras i Bages.

51. Ildefonso Gatell, escritor católico, eclesiástico catalán moderado y abierto a su época, es el autor de una Historia de la revolución de setiembre, editada en Barcelona en 1875 y cuyo otro autor es Eduardo Vilarrasa, uno de los colaboradores del Boletín de la Obra de Buenas Lecturas a partir de 1895.

52. Según datos publicados por el mismo Ildefonso Gatell, en 1904 y desde 1890 , la Obra de Buenas 
La Obra de Buenas Lecturas se dedicaba ante todo a la propaganda de la buena prensa, a organizar conferencias sobre temas de actualidad con la participación de laicos y eclesiásticos.

Indudablemente uno de los esfuerzos más notables de esta obra fue la publicación y la difusión de un Repertorio de Buenas Lecturas ${ }^{53}$ que empezó a publicarse en 1895. Contiene escritos de doctrina católica y también de "carácter moral y recreativo" así como artículos de la prensa católica nacional y extranjera. Este repertorio, que se publica mensualmente bajo la forma de un boletín, ofrece lecturas "cristianas y sanas" de la más pura ortodoxia: artículos del obispo de Jaca, Antolín López Peláez, del obispo de Vich, José Torras y Bages, del padre Cayetano Solers, del Cardenal Casañas. En la sección "Lecturas varias", los únicos ejemplos de literatura amena son los cuentos de José Pallés u obras selectas de Valbuena y Fray Luis de León así como las novelitas de la Familia Cristiana de Antonio Dubrull ${ }^{54}$.

En 1912, el mismo eclesiástico Ildefonso Gatell preside la Comisión de Prensa y Propaganda establecida en Barcelona por la Junta Diocesana de Acción Católica. Esta comisión estaba formada por varias secciones, encaminadas todas a difundir la buena prensa ${ }^{55}$. Una vez más, podemos constatar los vínculos existentes entre las distintas editoriales católicas y las asociaciones o apostolados de la buena prensa y de las buenas lecturas, ya que

Lecturas, "Había recaudado e invertido en publicaciones y propaganda 105.000 pesetas, publicado y distribuido unos 7.000.000 de ejemplares de La Hoja Dominical, 60.000 ejemplares del Repertorio de Buenas Lecturas, 650.000 del Amigo del Obrero y más de 300.000 entre libros, opúsculos y hojas con 45 títulos distintos". Boletín de la Obra de Buenas Lecturas, 1904, pp. 83-84.

53. Numerosos artículos de Ildefonso Gatell referentes al periodismo católico y más particularmente a la prensa católica popular se publican en este Repertorio desde 1895. Ponen de relieve la preocupación, por parte de la Iglesia española finisecular y de muchos católicos, por definir un periodismo católico capaz de competir con los grandes periodicos liberales de la época.

54. Otra vez quisiéramos destacar las semejanzas entre la situación de Francia y la de España en materia de periodismo católico y de las buenas lecturas, aunque existe un desfase notable entre las distintas iniciativas católicas de ambos países. Cabe señalar que el Repertorio de la Obra de Buenas Lecturas alude repetidas veces a los esfuerzos y los éxitos de la prensa católica francesa; entre otras cosas a la existencia de revistas católicas críticas, verdaderos repertorios de buenas lecturas. Citemos uno de los más conocidos, la Bibliographie catholique, revue critique des ouvrages de religion, de philosophie, d'histoire, de littérature, d'éducation, que se publicaba en París desde 1840. Esta revista anual estaba destinada a las "bibliothèques paroissales, aux cabinets de lecture chrétiens, aux pères et aux mères de famille, aux supérieurs de séminaires, aux chefs d'institution et de pension des deux sexes, et à toutes les personnes qui veulent connaître les bons livres et s'occuper de leur propagation".

55. Estas secciones eran: sección de Liga de Oraciones, sección de El Legionario, y sección de Buzones y de Publicaciones. En 1912, la sección de Publicaciones había editado 30.000 ejemplares de la hoja quincenal llamada Cultura Popular. En 1912, la Cofradía de los Legionarios encargada de la colecta de fondos para la buena prensa constaba de 472 "coros" y de 4.720 "legionarios".

Ildefonso Gatell, al presentar esta Comisión de Prensa y Propaganda en 1912, utiliza el mismo lenguaje que el que imperaba en 1870: "Para las luchas doctrinales de hoy, los católicos, los que pertenecemos a la Iglesia militante, no podemos desentendernos de estas luchas". 
era la revista carlista La Hormiga de Oro, fundada por Luis María de Llauder en 1884, la que difundía algunas de las publicaciones de la Acción Católica.

En cuanto a la sección de El Legionario, su finalidad era recaudar fondos para la agencia de prensa católica Prensa Asociada, fundada en 1909 por el Padre Dueso ${ }^{56}$.

Mencionemos también, muy brevemente para terminar, la existencia de una Cooperativa de la Buena Prensa en Barcelona, encaminada a recaudar fondos. Creada en 1905, esta asociación no vacila en proponer una colaboración "sana y puramente católica" a las casas comerciales que "tanto pueden en pro y en favor de esta clase de obras eminentemente prácticas" 57 .

Frente a la pujanza de la prensa liberal y a la desafición de los católicos con respecto a los medios tradicionales de propagación del dogma y de la doctrina católicos, los apostolados de la prensa y otras asociaciones surgieron como nuevos instrumentos de reclutamiento y control de los católicos.

Bajo la tutela de la jerarquía católica, estas asociaciones de la buena prensa están estrechamente vinculadas a las bibliotecas y editoriales católicas. En 1890, la Tipografía Católica publica la mayor parte de los periódicos y hojas sueltas de la Obra de Buenas Lecturas. El Repertorio de Buenas Lecturas publica casi exclusivamente las obras con licencia eclesiástica difundidas por la editorial católica Subirana de Barcelona.

Lo mismo ocurre con la prensa católica. La Hormiga de Oro, dirigida por el carlista Llauder, tiene su propio establecimiento tipográfico, "colocado bajo el patrocinio del Sagrado Corazón de Jesús".

Sin embargo, la prensa católica no cuenta, a finales del siglo XIX, con una verdadera organización empresarial. Los fracasos del periodismo católico, que se analizan y se deploran en la Asamblea de la Buena Prensa en Sevilla en 1904, se deben en gran parte a las enconadas contiendas que dividieron a los católicos y envenenaron la vida religiosa especialmente a partir de la Restauración. La prensa católica reflejó y promovió en muchas ocasiones estos enfrentamientos.

A partir de 1875 , el progresivo endurecimiento de carlistas e integristas que rechazaban las directrices del episcopado y las incitaciones de Roma, llegó a crear en el seno de la Iglesia española un cisma cuya gravedad está

56. Cabe mencionar otras iniciativas similares que habían surgido antes en distintas ciudades españolas: por ejemplo la del Cardenal Marcelo de Spínola, arzobispo de Sevilla, que fundó en 1898 la Asociación Diocesana de Buenas Lecturas y la Liga de Oraciones para trabajar y orar por la propaganda de la buena prensa.

57. "La creación de comités en los diez mil ayuntamientos de España, con sus juntas de Distrito y Provinciales, el Crédito e Información Comercial para todas las casas que tomando parte de esta Cooperativa presten su valioso concurso al desenvolvimiento y desarrollo de la Buena Prensa, será poderoso auxiliar en esta obra de trascedental importancia". Memoria acerca del objeto y fin de la Cooperativa General de la Buena Prensa, Barcelona, 1905. 
plasmada en la prensa católica de aquel período ${ }^{58}$.

Esta situación era particularmnte violenta en Cataluña, donde el sector integrista estaba muy arraigado y donde las revistas y los periódicos carlistas e integristas se opusieron sistemáticamente a la Restauración y al sector católico que veía con buenos ojos la Unión Católica de Pidal.

La prensa católica catalana que se publica de 1875 hasta finales del siglo tiene un carácter marcadamente ideológico-político. Las publicaciones católicas más moderadas y conformes con las nuevas orientaciones conciliadoras de León XIII no pudieron rehuir este contexto de constantes enfrentamientos. Incluso revistas como El Criterio Católico, dirigida por Eduardo Llanas, de signo moderado, se enzarza en acerbas polémicas con la Revista Popular y La Hormiga de Oro.

Estos antagonismo y ataques personales esterilizaron por completo los primeros conatos de organización del periodismo católico a escala local o nacional.

58. En una de sus encíclicas más importantes, la Cum Multa de 1882, León XIII lanza graves advertencias a la prensa y a los periodistas católicos en general y se refiere implícitamente a la situación española: "Y como nada más contrario hay a la concordia que el desabrimiento en el hablar, la temeridad en sospechar y la malicia en acriminar, es preciso evitar todo esto con suma precaución. Las disputas en defensa de los sagrados derechos de la Iglesia no se hagan con altercados, sino con moderación y con templanza". Encíclica Cum Multa a los Venerables hermanos y a los queridos hijos los Arzobispos, Obispos y demás ordinarios de la región de España, 8 de diciembre 1882. 